\title{
Benign Penile Neoplasm
}

National Cancer Institute

\section{Source}

National Cancer Institute. Benign Penile Neoplasm. NCI Thesaurus. Code C3489.

A non-metastasizing neoplasm that arises from the penis. Representative examples include hemangioma and lymphangioma. 